\title{
CARACTERÍSTICAS DE UM LATOSSOLO VERMELHO SOB PASTAGEM NATURAL SUJEITA À AÇÃO PROLONGADA DO FOGO E DE PRÁTICAS ALTERNATIVAS DE MANEJO ${ }^{1}$
}

\author{
CHARACTERISTICS OF AN OXISOL UNDER NATIVE PASTURE SUBMITTED \\ TO FIRE FOR LONG TIME AND ALTERNATIVE MANAGEMENTS
}

\author{
Ingrid Heringer $^{2}$ Aino Victor Ávila Jacques ${ }^{3}$ Carlos Alberto Bissani ${ }^{4}$ \\ Marino Tedesco 5
}

RESUMO

Foram coletadas, em 1998, amostras de solo nas camadas de 0-2,5; 2,5-5,0; 5-10 e 10-30 cm, em pastagem natural manejada sob queima sistemática e com distintas alternativas de manejo em relação às queimadas (sem queima, com ou sem rocada, $e$ melhorado com calagem, adubação e introdução de espécies, há 7 e 24 anos), na região dos Campos de Cima da Serra, RS. O delineamento experimental foi o inteiramente casualizado com três repetições. $O$ melhoramento da pastagem natural elevou os teores de $\mathrm{Ca}, \mathrm{Mg}$ e $\mathrm{P}$ no solo, a saturação de bases e o pH e reduziu a acidez potencial. A queima da pastagem natural, em relação às demais áreas sem queima e sem melhoramento, promoveu aumento na acidez potencial e redução nos teores de magnésio na camada mais superficial do solo. A prática de roçada, por um lado aumenta o teor de Mg e a saturação de bases; e por outro, reduz a acidez potencial na superfície do solo, em relação ao solo de pastagem queimada ou só pastejada e sem roçada. Sistemas sem queima apresentam maior quantidade de água e cobertura do solo.

Palavras-chave: fertilidade do solo, manejo, queimada, melhoramento da pastagem.

\section{SUMMARY}

Soil samples were taken, in 1998, from distinct layers $(0-2.5 ; 2.5-5.0 ; 5-10$ and $10-30 \mathrm{~cm})$ in fields with native pasture under grazing, submitted to burning and alternative management practices (without burning with or without mowing, and improved for 7 and 24 years), in the Campos de Cima da Serra region, $R S$, Brazil. The experimental design was a completely randomized, with three replications. The improvement of native pasture increased the value of $\mathrm{pH}$ and the levels $\mathrm{Ca}, \mathrm{Mg}$, $P$ and base saturation, and reduced the potential acidity. Biennial burning increased the potential acidity and reduced $\mathrm{Mg}$. The mowing treatment increased the level of $\mathrm{Mg}$ and base saturation, and decreased the potencial acidity in the soil surface in comparison to the system without burning and without mowing. Systems without burning were more efficient in water conservation and soil cover.

Key words: soil fertilizing, management, burning, improvement pasture

\section{INTRODUÇÃO}

A queima das pastagens é um dos manejos cujos efeitos no solo têm sido negligenciados tanto pela pesquisa quanto pelos produtores. Pesquisas realizadas em áreas pouco representativas e sem histórico conhecido de queimadas (RAISON, 1979) conduzem a conclusões precipitadas ou equivocadas.

Em áreas onde o uso da queima é sistemático, a quantidade e a composição dos nutrientes que ciclam no solo dependem do regime de queimadas. Seus efeitos são percebidos através da incorporação de cinzas, redução da cobertura e aquecimento do solo. Indiretamente, as mudanças

\footnotetext{
${ }^{1}$ Artigo extraído da Tese de Doutorado apresentada à Universidade Federal do Rio Grande do Sul (UFRGS), pelo primeiro autor, como um dos requisitos para a obtenção do grau de Doutor em Zootecnia, Projeto financiado pelo CNPq.

${ }^{2}$ Zootecnista, Doutor, Rua Coronel Passos Mais, 1103/103, 89820-000, Xanxerê-SC. E-mail renato@prezzotto.com.br

${ }^{3}$ Engenheiro Agrônomo, PhD., Professor Titular do Departamento de Plantas Forrageiras e Agrometeorologia, Pesquisador do CNPq, UFRGS.

${ }^{4}$ Engenheiro Agrônomo, PhD., Professor Adjunto do Departamento de Solos, UFRGS.

${ }^{5}$ Engenheiro Agrônomo, PhD., Professor Titular do Departamento de Solos, UFRGS. 
provocadas na composição, na forma e na produtividade da vegetação podem alterar algumas propriedades do solo em função do estímulo ao crescimento de algumas plantas e do surgimento de espécies pioneiras (RAISON, 1979).

A curto prazo, a elevação da temperatura do solo induz ao aumento na taxa de decomposição dos resíduos e na taxa de mineralização da matéria orgânica (MO) (SCHACHT et al., 1996). Nesta fase, muitos elementos nutricionais ligados e complexados à MO são mineralizados e tornam-se facilmente disponíveis, tais com $\mathrm{NH}_{4}, \mathrm{P}$ inorgânico, $\mathrm{Na}, \mathrm{Ca}, \mathrm{Mg}$ e parte do K (COUTINHO, 1994; GIRARDI-DEIRO et al., 1994). Como resultado desse processo, a longo prazo, pode ocorrer decréscimo da capacidade de troca de cátions (CTC) e do teor de MO (GIOVANNINI E LUCCHESI, 1997). A elevação do pH do solo após a queima deve-se ao efeito das cinzas, que reduzem temporariamente os teores de $\mathrm{Al}$ (COUTINHO, 1994) e de ácidos orgânicos e, ao mesmo tempo, aumentam a saturação de bases na superfície do solo (SCHACHT et al., 1996). A queima também afeta a estacionalidade e forma disponível de alguns elementos minerais no solo.

Quanto aos impactos do fogo sobre as propriedades físicas do solo, observa-se que, após a queima, geralmente uma reduzida cobertura vegetal permanece para dissipar a energia da queda da chuva, e para obstruir o escorrimento superficial. O maior volume de escorrimento, associado com o decréscimo na taxa de infiltração, explica o aumento nas perdas de solo em áreas queimadas (HESTER $\boldsymbol{e t}$ al., 1997). As substâncias hidrofóbicas formadas durante a queima tornam-se fortemente cimentadas na camada subsuperficial do solo (GIOVANNINI $\boldsymbol{e} t$ al., 1987), podendo resultar na formação de camadas repelentes à água e aumento do potencial de perdas por erosão (MACEDO, 1995).

Nesse sentido, o presente trabalho tem como objetivo avaliar a taxa de cobertura, umidade volumétrica e características químicas do solo sob pastagem natural e distintas condições de manejo.

\section{MATERIAL E MÉTODOS}

Foram selecionadas cinco áreas de pastagem natural conduzida sob distintos manejos, no município de André da Rocha, RS, na região fisiográfica dos Campos de Cima da Serra, a uma altitude aproximada de $800 \mathrm{~m}$, a $28^{\circ} 38^{\prime}$ de latitude Sul e 58 $34^{\prime}$ 'de longitude Oeste. O clima da região é temperado úmido $(\mathrm{Cfb})$, com verões amenos. A vegetação natural é típica da região, representando uma transição entre o campo e a mata, com predominância de gramíneas cespitosas.

O solo das áreas estudadas é um Latossolo Vermelho Distroférrico típico (EMBRAPA, 1999), de textura argilosa, pertencente à Unidade de Mapeamento Durox. Caracteriza-se quimicamente pela baixa saturação de bases, deficiência de $\mathrm{P}$, teores altos de matéria orgânica e níveis tóxicos de alumínio.

As áreas levantadas constaram de pastagem natural pastejada sob os seguintes manejos: sem queima há 32 anos e sem roçada (SQSR); sem queima há 32 anos e roçada anualmente; melhorada há sete anos (CNM 7 anos); melhorada há 24 anos (CNM 24 anos); e queimada numa freqüência bienal há mais de 100 anos (testemunha). Em cada tratamento foi delimitado um sítio, o qual foi subdividido em três subáreas para realização das amostragens. Os sítios escolhidos para as avaliações foram de 10 x $30 \mathrm{~m}$, situados topograficamente na encosta de cada potreiro, cuja situação é a mais representativa do relevo da região. $\mathrm{O}$ delineamento experimental foi $\mathrm{o}$ inteiramente casualizado com três repetições.

O solo da área CNM 24 anos recebeu, em 1973, preparo convencional, calagem e adubação, seguidos da semeadura de festuca (Festuca elatior Schreb.) e trevo branco (Trifolium repens L.). De 1978 a 1984, a área só foi pastejada. Em 1984, foi roçada, gradeada, recebeu três $\mathrm{t} \mathrm{ha}^{-1}$ de calcário dolomítico, quando foram semeados trevo branco e trevo vermelho (T. pratense L.). A partir de 1984, foram aplicadas, em média, duas e meia $\mathrm{t} \mathrm{ha}^{-1} \mathrm{de}$ calcário dolomítico na superfície da pastagem (sem revolvimento do solo) a cada quatro anos e realizadas adubações anuais de manutenção com $200 \mathrm{~kg} \mathrm{ha}^{-1}$ das fórmulas 10-30-10 ou 5-30-15. De 1995 a 1997, a adubação de manutenção foi reduzida a $100 \mathrm{~kg} \mathrm{ha}^{-1} \mathrm{ano}^{-1}$ da fórmula 5-30-15. A área do CNM 7 anos segue o mesmo manejo da área anterior, porém sempre com preparo superficial do solo e introdução de trevo branco e trevo vermelho a partir de 1991.

A amostragem do solo foi realizada em 16 de abril de 1998, retirando-se 3 amostras compostas por área experimental. As amostras foram retiradas nas seguintes camadas: $0-2,5 ; 2,5-5 ; 5-10$ e 10 $30 \mathrm{~cm}$. As amostras da camada de $0-10 \mathrm{~cm}$ foram retiradas com pá de corte e seccionadas em fatias com facão nas profundidades pretendidas. $\mathrm{Na}$ camada de $10-30 \mathrm{~cm}$ as amostras foram retiradas com trado de rosca. O solo foi seco ao ar e encaminhado ao Laboratório de Análises de Solo e Tecido Vegetal da Faculdade de Agronomia da UFRGS, onde foram realizadas as seguintes determinações: $\mathrm{pH}\left(\mathrm{H}_{2} \mathrm{O}\right)$; 
fósforo e potássio extraíveis (Mehlich-1); matéria orgânica; alumínio; cálcio e magnésio trocáveis; acidez potencial $(\mathrm{H}+\mathrm{Al})$; CTC; e saturação por bases e Al (TEDESCO et al., 1995).

A cobertura do solo foi estimada a cada 45 dias, de setembro de 1997 a setembro de 1998, percorrendo-se cada área e estimando-se visualmente a percentagem de solo descoberto. A quantidade de água volumétrica do solo foi determinada em dez pontos dentro de cada tratamento, na camada de $0-15 \mathrm{~cm}$, com o equipamento TDR, modelo Trase $6050 \mathrm{X} 1$, tipo Soil Moisture. As avaliações foram realizadas em 07 de dezembro de 1998, após aproximadamente 30 dias de estresse hídrico. de variância, e as diferenças e/ou interações significativas ao nível de 5\% ensejaram a aplicação do teste de Waller-Duncan.

\section{RESULTADOS E DISCUSSÃO}

Os sistemas de manejo SQSR, roçado e queimado, apresentaram valores de $\mathrm{pH}$ similares ao longo do perfil de solo avaliado $(\mathrm{P}>0,05)$. No $\mathrm{CNM}$ 24 anos, ocorreu uma uniformização do $\mathrm{pH}$ do solo até a camada média de $10-30 \mathrm{~cm}$ (Tabela 1 ), em
A metodologia estatística incluiu análise

função da maior quantidade acumulada de calcário ao longo do período de melhoramento. No CNM 7 anos o $\mathrm{pH}$ foi 0,4 unidade superior na camada de 0 $5,0 \mathrm{~cm}$ em relação ao CNM 24 anos, permanecendo o $\mathrm{pH}$ praticamente igual entre estes tratamentos nas demais camadas.

Em relação ao teor de alumínio trocável (Tabela 1), observou-se comportamento similar ao do $\mathrm{pH}$. No CNM 7 anos, o $\mathrm{Al}$ apareceu a partir da camada de $5 \mathrm{~cm}$, porém, em valores muito baixos, com saturação de $\mathrm{Al}$ inferior a $10 \%$. O CNM 24 anos teve concentração de 0,3 a $0,6 \mathrm{cmol}_{\mathrm{c}} \mathrm{L}^{-1}$ de $\mathrm{Al}$, com saturação por Al chegando a 4,2\% nas camadas mais profundas. $\mathrm{O}$ teor de $\mathrm{Al}$ trocável, a acidez potencial e a saturação por $\mathrm{Al}$ tenderam a ser sempre maiores no solo de campo nativo queimado em relação aos demais tratamentos.

A área roçada apresentou menor saturação por alumínio na camada de $0-5,0 \mathrm{~cm}$, em relação aos outros tratamentos que também não receberam correção do solo, se assemelhando a estes nas camadas mais profundas. O retorno de palha através da roçada parece contribuir para um acréscimo na quantidade de bases no solo, reduzindo a acidez potencial, mesmo apresentando $\mathrm{pH}$ semelhante aos outros tratamentos sem correção. Demonstram-se em experimentos que há uma dinâmica diferenciada dos nutrientes no sistema plantio direto, onde há maior acúmulo de restos vegetais na superfície do solo (SALET et al., 1996).

Os menores teores de $\mathrm{Ca}$, manejos

Camada Sem queima Sem queima Melhorado Melhorado Queima há mais $(\mathrm{cm})$ e sem roçada e roçado há 24 anos há 7 anos de 100 anos

\begin{tabular}{|c|c|c|c|c|c|}
\hline \multirow[b]{2}{*}{$0-2,5$} & \multicolumn{5}{|c|}{$\mathrm{pH}\left(\mathrm{H}_{2} \mathrm{O}\right)$} \\
\hline & $4,8 \mathrm{c}$ & $4,8 \mathrm{c}$ & $5,5 \mathrm{~b}$ & $5,9 \mathrm{a}$ & $4,7 \mathrm{c}$ \\
\hline $2,5-5$ & $4,7 \mathrm{c}$ & $4,7 \mathrm{c}$ & $5,4 \mathrm{~b}$ & $5,8 \mathrm{a}$ & $4,7 \mathrm{c}$ \\
\hline $5-10$ & $4,7 \mathrm{~b}$ & $4,7 \mathrm{~b}$ & $5,4 \mathrm{a}$ & $5,3 \mathrm{a}$ & $4,7 \mathrm{~b}$ \\
\hline \multirow[t]{2}{*}{$10-30$} & $4,7 \mathrm{~b}$ & $4,7 \mathrm{~b}$ & $5,3 \mathrm{a}$ & $5,2 \mathrm{a}$ & $4,7 \mathrm{~b}$ \\
\hline & \multicolumn{5}{|c|}{$\mathrm{Al}$ trocável $\left(\mathrm{cmol}_{\mathrm{c}} \mathrm{L}^{-1}\right)$} \\
\hline $0-2,5$ & $3,1 \mathrm{a}$ & $2,1 \mathrm{~b}$ & $0,4 \mathrm{c}$ & $0,0 \mathrm{c}$ & $3,8 \mathrm{a}$ \\
\hline $2,5-5$ & $3,5 \mathrm{~b}$ & $3,1 \mathrm{~b}$ & $0,3 \mathrm{c}$ & $0,0 \mathrm{c}$ & $4,5 \mathrm{a}$ \\
\hline $5-10$ & $3,6 \mathrm{a}$ & $3,7 \mathrm{a}$ & $0,5 \mathrm{~b}$ & $0,7 \mathrm{~b}$ & $4,1 \mathrm{a}$ \\
\hline \multirow[t]{2}{*}{$10-30$} & $3,8 \mathrm{~b}$ & $4,0 \mathrm{~b}$ & $0,6 \mathrm{~d}$ & $1,4 \mathrm{c}$ & $4,7 \mathrm{a}$ \\
\hline & \multicolumn{5}{|c|}{$\mathrm{Al}+\mathrm{H}\left(\mathrm{cmol}_{\mathrm{c}} \mathrm{L}^{-1}\right)$} \\
\hline $0-2,5$ & $11,9 \mathrm{~b}$ & $9,3 \mathrm{c}$ & $5,6 \mathrm{~d}$ & $4,1 \mathrm{~d}$ & $13,8 \mathrm{a}$ \\
\hline $2,5-5$ & $13,0 \mathrm{a}$ & $12,6 \mathrm{a}$ & $5,7 \mathrm{~b}$ & $4,3 \mathrm{~b}$ & $13,8 \mathrm{a}$ \\
\hline $5-10$ & $12,7 \mathrm{a}$ & $13,4 \mathrm{a}$ & $5,8 \mathrm{a}$ & $5,9 \mathrm{a}$ & $13,9 \mathrm{a}$ \\
\hline \multirow[t]{2}{*}{$10-30$} & $13,4 \mathrm{~b}$ & $12,6 \mathrm{~b}$ & $5,7 \mathrm{~d}$ & $8,3 \mathrm{c}$ & $15,6 \mathrm{a}$ \\
\hline & \multicolumn{5}{|c|}{ Saturação por $\mathrm{Al}(\%)$} \\
\hline $0-2,5$ & $20,6 a b$ & $14,5 \mathrm{~b}$ & $2,3 \mathrm{c}$ & $0,0 \mathrm{c}$ & $24,1 \mathrm{a}$ \\
\hline $2,5-5$ & $22,4 \mathrm{~b}$ & $18,8 \mathrm{c}$ & $2,1 \mathrm{~d}$ & $0,0 \mathrm{~d}$ & $29,2 \mathrm{a}$ \\
\hline $5-10$ & $23,7 \mathrm{a}$ & $23,8 \mathrm{a}$ & $3,6 \mathrm{~b}$ & $5,0 \mathrm{~b}$ & $25,7 \mathrm{a}$ \\
\hline $10-30$ & $24,5 \mathrm{a}$ & $27,0 \mathrm{a}$ & $4,2 \mathrm{c}$ & $9,7 \mathrm{~b}$ & $28,3 \mathrm{a}$ \\
\hline
\end{tabular}

Médias seguidas por letras distintas na mesma linha diferem entre si pelo teste de Waller-Duncan a um nível de $5 \%$ de probabilidade.
$\mathrm{Mg}$ e saturação por bases na superfície do solo $(0-5 \mathrm{~cm})$ do CNM 24 anos em relação ao CNM 7 anos podem ser explicados pelo maior retorno de restos vegetais no melhoramento mais antigo. Nessas condições, há aumento na velocidade de deslocamento dos produtos de reações do calcário e dos adubos, os quais aparecem em maiores quantidades nas camadas subsuperficiais.

A aplicação de calcário na pastagem natural promoveu o aumento de $\mathrm{Ca}$ e $\mathrm{Mg}$ em até 6 vezes na camada de $0-2,5 \mathrm{~cm} \quad(\mathrm{P}<0,05)$. Esses teores se mantiveram elevados até a camada de 10-30cm (Tabela 2). Na camada de 0$5 \mathrm{~cm}$, os teores de $\mathrm{Ca}$ e $\mathrm{Mg}$ foram superiores no CNM 7 anos $(\mathrm{P}<0,05)$, em relação ao CNM 24 anos, invertendo-se na camada de $10-30 \mathrm{~cm}$. Observaram-se teores similares de $\mathrm{Ca}$ solo $(\mathrm{P}>0,05)$. Em relação ao $\mathrm{Mg}$, nos entre os tratamentos sem correção do 
Tabela 2 - Teores de cálcio, magnésio, potássio e saturação por bases em diferentes camadas do solo, em pastagem natural sob distintos manejos.

\begin{tabular}{|c|c|c|c|c|c|}
\hline $\begin{array}{l}\text { Camada } \\
(\mathrm{cm})\end{array}$ & $\begin{array}{l}\text { Sem queima } \\
\text { e sem roçada }\end{array}$ & $\begin{array}{l}\text { Sem queima } \\
\text { e roçado }\end{array}$ & $\begin{array}{l}\text { Melhorado } \\
\text { há } 24 \text { anos }\end{array}$ & $\begin{array}{l}\text { Melhorado } \\
\text { há } 7 \text { anos }\end{array}$ & $\begin{array}{l}\text { Queima há mais } \\
\text { de } 100 \text { anos }\end{array}$ \\
\hline & \multicolumn{5}{|c|}{$\mathrm{Ca}_{\text {trocável }}\left(\mathrm{cmol}_{\mathrm{c}} \mathrm{L}^{-1}\right)$} \\
\hline $0-2,5$ & $1,6 \mathrm{c}$ & $2,5 \mathrm{c}$ & $6,4 \mathrm{~b}$ & $8,3 \mathrm{a}$ & $1,1 \mathrm{c}$ \\
\hline $2,5-5$ & $1,2 \mathrm{c}$ & $1,7 \mathrm{c}$ & $6,0 \mathrm{~b}$ & $7,2 \mathrm{a}$ & $0,8 \mathrm{c}$ \\
\hline $5-10$ & $1,1 \mathrm{~b}$ & $1,1 \mathrm{~b}$ & $5,2 \mathrm{a}$ & $4,6 \mathrm{a}$ & $0,9 \mathrm{~b}$ \\
\hline \multirow[t]{2}{*}{$10-30$} & $1,0 \mathrm{c}$ & $1,1 \mathrm{c}$ & $5,2 \mathrm{a}$ & $3,3 \mathrm{~b}$ & $0,6 \mathrm{c}$ \\
\hline & \multicolumn{5}{|c|}{$\mathrm{Mg}_{\text {trocável }}\left(\mathrm{cmol}_{\mathrm{c}} \mathrm{L}^{-1}\right)$} \\
\hline $0-2,5$ & $1,4 \mathrm{~cd}$ & $2,2 \mathrm{c}$ & $4,2 \mathrm{~b}$ & $5,8 \mathrm{a}$ & $0,7 \mathrm{~d}$ \\
\hline $2,5-5$ & $1,1 \mathrm{~cd}$ & $1,5 \mathrm{c}$ & $3,7 \mathrm{~b}$ & $5,0 \mathrm{a}$ & $0,5 \mathrm{~d}$ \\
\hline $5-10$ & $1,0 \mathrm{~b}$ & $0,7 \mathrm{~b}$ & $3,5 \mathrm{a}$ & $3,3 \mathrm{a}$ & $0,7 \mathrm{~b}$ \\
\hline \multirow[t]{2}{*}{$10-30$} & $0,9 \mathrm{c}$ & $0,7 \mathrm{c}$ & $3,4 \mathrm{a}$ & $2,5 \mathrm{~b}$ & $0,3 \mathrm{c}$ \\
\hline & \multicolumn{5}{|c|}{$\mathrm{K}\left(\mathrm{mg} \mathrm{L}^{-1}\right)$} \\
\hline $0-2,5$ & $142,7 \mathrm{a}$ & $247,7 \mathrm{a}$ & $208,0 \mathrm{a}$ & $113,7 \mathrm{a}$ & $136,7 \mathrm{a}$ \\
\hline $2,5-5$ & $167,7 \mathrm{a}$ & $182,7 \mathrm{a}$ & $122,0 \mathrm{a}$ & $92,7 \mathrm{a}$ & $100,7 \mathrm{a}$ \\
\hline $5-10$ & $119,3 \mathrm{a}$ & $139,0 \mathrm{a}$ & $92,0 \mathrm{a}$ & $68,3 \mathrm{a}$ & $130,7 \mathrm{a}$ \\
\hline \multirow[t]{2}{*}{$10-30$} & $106,7 \mathrm{a}$ & $111,3 \mathrm{a}$ & $84,3 \mathrm{ab}$ & $62,3 \mathrm{bc}$ & $47,3 \mathrm{c}$ \\
\hline & \multicolumn{5}{|c|}{ Saturação por bases (\%) } \\
\hline $0-2,5$ & $22,0 \mathrm{c}$ & $36,3 \mathrm{~b}$ & $66,3 \mathrm{a}$ & $77,3 \mathrm{a}$ & $13,3 \mathrm{c}$ \\
\hline $2,5-5$ & $16,7 \mathrm{~cd}$ & $22,3 \mathrm{c}$ & $64,0 \mathrm{~b}$ & $74,3 \mathrm{a}$ & $9,7 \mathrm{~d}$ \\
\hline $5-10$ & $16,3 \mathrm{~b}$ & $13,3 \mathrm{~b}$ & $60,0 \mathrm{a}$ & $57,3 \mathrm{a}$ & $12,7 \mathrm{~b}$ \\
\hline $10-30$ & $13,7 \mathrm{c}$ & $14,3 \mathrm{c}$ & $60,7 \mathrm{a}$ & $42,0 \mathrm{~b}$ & $6,3 \mathrm{c}$ \\
\hline
\end{tabular}

Médias seguidas por letras distintas na mesma linha diferem entre si pelo teste de Waller-Duncan a um nível de $5 \%$ de probabilidade.

sistemas sem correção do solo, verificaram-se teores menores do nutriente no solo da pastagem natural queimada, intermediários no SQSR, e maiores no roçado, para a camada de $0-5 \mathrm{~cm}$, sem diferença a partir daí. Como o Mg é mais móvel em relação ao $\mathrm{Ca}$, é mais facilmente perdido na área queimada, que mantém maior superfície de solo descoberto.

Os efeitos da calagem nas áreas melhoradas, em termos de elevar o $\mathrm{pH}$, reduzir o $\mathrm{Al}$ e aprofundar $\mathrm{Ca}$ e $\mathrm{Mg}$, não ficaram restritos somente à superfície do solo, distinguindo-se das observações usualmente feitas no sistema de plantio direto, em que os efeitos do calcário ocorrem somente até poucos centímetros abaixo das camadas onde é incorporado ao solo (STECKLING \& ERNANI, 1998). Com esses dados, estimou-se que os produtos da reação do calcário desceram no perfil do solo numa velocidade superior a $4 \mathrm{~cm} \mathrm{ano}^{-1}$. A alta quantidade de raízes na pastagem, bem como a maior ciclagem de restos vegetais e de dejeções de animais, contribuem apreciavelmente para uma dinâmica mais intensa dos nutrientes no solo de pastagens em relação ao de lavouras (TRACY \& FRANK, 1998). O deslocamento de partículas de calcário, ou produtos de sua reação, é favorecido pela porosidade contínua no perfil (GASSEN \& KOCHANN, 1998), a qual tende a ser maior nos solos sob pastagem, que sofrem pouco ou nenhum revolvimento.
Não houve diferença estatística entre sistemas de manejo para os teores de $\mathrm{K}$ do solo $(\mathrm{P}<0,05)$, à exceção da camada de $10-30 \mathrm{~cm}$ (Tabela 2), com concentrações maiores nos tratamentos sem queima e roçado, inferiores no queimado, e intermediários nos melhorados. Embora a maior parte do $\mathrm{K}$ retornasse ao solo em áreas pastejadas, seus teores no solo não foram alterados nos sistemas de manejo com melhoramento da pastagem nativa. Pressupõe-se que a tendência de teores menores de $\mathrm{K}$ no solo das áreas melhoradas foi devido aos valores mais elevados de $\mathrm{Ca}$ e $\mathrm{Mg}$ destas áreas, os quais concorrem com o $\mathrm{K}$ nos sítios de troca de cátions.

O comportamento da saturação por bases no perfil do solo sob diferentes sistemas de manejo foi semelhante àquele observado para $\mathrm{Ca} \mathrm{e}$ $\mathrm{Mg}$ e inverso ao do $\mathrm{Al}$ trocável. A saturação de bases no CNM 24 anos foi igual ou superior a $60 \%$ ao longo de todo o perfil estudado, enquanto no CNM 7 anos houve um gradiente a partir de $5 \mathrm{~cm}$, quando cai de $74,3 \%$ para $42 \%$ na camada de $10-30 \mathrm{~cm}$. O solo da área roçada destacou-se entre os sistemas sem correção do solo, apresentando na camada de $0-5 \mathrm{~cm}$ saturação de bases maior, o queimado menor e o SQSR intermediária $(\mathrm{P}<0,05)$. A tendência de menores teores de $\mathrm{Ca}, \mathrm{Mg}$ e desaturação por bases na área queimada foi consistente. Com a queima, grande parte do solo fica descoberto e desprotegido do impacto das gotas de chuva, por um longo período de tempo. Sob tais condições, o risco de perdas de nutrientes por erosão é muito grande.

Quanto ao teor de MO do solo (Tabela 3), a análise estatística apontou diferença entre tratamentos somente na camada de $2,5-5 \mathrm{~cm}$, com teores superiores no CNM 7 anos, seguido do queimado, o qual não diferiu dos demais tratamentos $(\mathrm{P}<0,05)$. O teor de MO foi alto e, de maneira geral, não foi afetado pelos sistemas de manejo, sendo característico de solos com alto teor de argila, sem mobilização e de regiões com temperaturas amenas, que reduzem as taxas de mineralização. Nesta condição, a maioria dos componentes orgânicos pode persistir no solo por anos, especialmente naquele com baixa atividade biológica, devido à sua estabilidade química (FERNANDES et al., 1997).

Em pastagens, o conteúdo de MO do solo tende a se manter estável, ou então aumentar. As 
Tabela 3 - Teores de matéria orgânica, capacidade de troca de cátions e fósforo em diferentes camadas do solo, em pastagem natural sob distintos manejos.

\begin{tabular}{lccccc}
\hline $\begin{array}{l}\text { Camada } \\
(\mathrm{cm})\end{array}$ & $\begin{array}{c}\text { Sem queima } \\
\text { e sem roçada }\end{array}$ & $\begin{array}{c}\text { Sem queima } \\
\text { e roçado }\end{array}$ & $\begin{array}{c}\text { Melhorado } \\
\text { há } 24 \text { anos }\end{array}$ & $\begin{array}{c}\text { Melhorado } \\
\text { há } 7 \text { anos }\end{array}$ & $\begin{array}{c}\text { Queima há mais } \\
\text { de } 100 \text { anos }\end{array}$ \\
\hline \multicolumn{5}{c}{ MO $(\%)$} \\
$0-2,5$ & $6,5 \mathrm{a}$ & $6,8 \mathrm{a}$ & $6,9 \mathrm{a}$ & $7,9 \mathrm{a}$ & $6,9 \mathrm{a}$ \\
$2,5-5$ & $5,8 \mathrm{~b}$ & $6,0 \mathrm{~b}$ & $5,8 \mathrm{~b}$ & $6,8 \mathrm{a}$ & $6,3 \mathrm{ab}$ \\
$5-10$ & $5,5 \mathrm{a}$ & $5,4 \mathrm{a}$ & $5,5 \mathrm{a}$ & $5,7 \mathrm{a}$ & $6,2 \mathrm{a}$ \\
$10-30$ & $5,8 \mathrm{a}$ & $5,2 \mathrm{a}$ & $5,8 \mathrm{a}$ & $5,5 \mathrm{a}$ & $6,0 \mathrm{a}$ \\
& & \multicolumn{5}{c}{} & \\
$0-2,5$ & $15,3 \mathrm{bc}$ & $14,7 \mathrm{c}$ & $16,7 \mathrm{ab}$ & $18,4 \mathrm{a}$ & $16,0 \mathrm{bc}$ \\
$2,5-5$ & $15,7 \mathrm{a}$ & $16,2 \mathrm{a}$ & $15,8 \mathrm{a}$ & $16,7 \mathrm{a}$ & $15,3 \mathrm{a}$ \\
$5-10$ & $15,1 \mathrm{ab}$ & $15,5 \mathrm{ab}$ & $14,6 \mathrm{ab}$ & $14,0 \mathrm{~b}$ & $15,8 \mathrm{a}$ \\
$10-30$ & $15,5 \mathrm{a}$ & $14,7 \mathrm{a}$ & $14,5 \mathrm{a}$ & $14,3 \mathrm{a}$ & $16,5 \mathrm{a}$ \\
& & & & \\
$0-2,5$ & $2,1 \mathrm{~b}$ & $2,2 \mathrm{~b}$ & $8,0 \mathrm{a}$ & $9,8 \mathrm{a}$ & $1,7 \mathrm{~b}$ \\
$2,5-5$ & $1,5 \mathrm{c}$ & $2,0 \mathrm{c}$ & $4,0 \mathrm{~b}$ & $6,0 \mathrm{a}$ & $1,4 \mathrm{c}$ \\
$5-10$ & $1,2 \mathrm{~b}$ & $0,8 \mathrm{~b}$ & $2,6 \mathrm{a}$ & $2,8 \mathrm{a}$ & $1,2 \mathrm{~b}$ \\
$10-30$ & $1,0 \mathrm{~b}$ & $0,7 \mathrm{~b}$ & $3,6 \mathrm{a}$ & $2,3 \mathrm{ab}$ & $1,0 \mathrm{~b}$ \\
\hline
\end{tabular}

Médias seguidas por letras distintas na mesma linha diferem entre si pelo teste de Waller-Duncan a um nível de $5 \%$ de probabilidade.

práticas de manejo geralmente têm grande efeito na reserva de $\mathrm{C}$ no solo, mas pequenas e graduais mudanças são difíceis de detectar a curto prazo, devido à alta reciclagem e variabilidade no solo (SEASTEDT et al., 1994). O histórico de queimadas da vegetação sobre um solo com alta quantidade de argila pode ser insuficiente para se detectarem mudanças na fração $\mathrm{MO}$, em razão da forte associação desta com as partículas minerais (FELLER \& BEARE, 1997). A medida do $\mathrm{C}$ da biomassa microbiana, neste sentido, seria um indicador mais sensível do que o $\mathrm{C}$ orgânico total do solo.

Somente na superfície do solo o calcário aumentou a CTC, promovendo um acréscimo de cargas negativas nas partículas do solo. Nas demais camadas, não houve comportamento tão distinto da CTC. Na camada de $5-10 \mathrm{~cm}$, só a área queimada apresentou maior CTC, o qual está associado a um nível de MO que também tende a ser superior nesta camada e tratamento. Os elevados teores de MO em todos os sistemas de manejo fizeram com que a CTC tivesse pouca variação entre tratamentos, e a correção do solo (elevação de $\mathrm{Ca}$ e $\mathrm{Mg}$ nos tratamentos melhorados) parece ter sido compensada pelos teores médios superiores de $\mathrm{Al}$ e $\mathrm{K}$ nos tratamentos sem correção.

Os teores de $\mathrm{P}$ foram maiores ao longo de todo o perfil avaliado no solo de campo nativo melhorado em relação ao não melhorado (Tabela 3). Nos sistemas melhorados o fósforo deslocou-se até a última camada amostrada (10-30cm), enquanto o $\mathrm{P}$ nativo do solo, na camada de $0-2,5 \mathrm{~cm}$, esteve em torno de $2 \mathrm{mg} \ell^{-1}$, chegou a valores 4 a 5 vezes maiores nas áreas melhoradas. Nos sistemas sem melhoramento da pastagem natural, os teores de $\mathrm{P}$ foram similares $(\mathrm{P}>0,05)$.

$\mathrm{O}$ teor de $\mathrm{P}$ é variável em áreas já fertilizadas, em função das quantidades aplicadas ao longo dos anos, e seu efeito residual é decorrente da baixa necessidade das culturas (ERNANI, 1999). Embora a quantidade acumulada de P no CNM 24 anos fosse superior ao CNM 7 anos, este efeito foi percebido mais no deslocamento de $\mathrm{P}$ no perfil do solo, do que nas camadas superficiais.

$\mathrm{Na}$ análise conjunta das variáveis relacionadas à química do solo da pastagem natural sob manejo diferenciado, observou-se que a queima continuada tendeu a alterar a concentração de alguns nutrientes importantes. Portanto, esses dados contrastam com as observações e os comentários sobre os benefícios da queima em termos de corrigir o solo e aumentar a oferta de nutrientes no meio (RAISON, 1979; COUTINHO, 1994; SCHACHT et al., 1996).

Avaliou-se a cobertura do solo através de estimativas visuais sobre as porções de solo descoberto (sem cobertura de plantas ou mantilho). Os tratamentos sem queima apresentaram cobertura total do solo e diferenciaram-se da área queimada, que sempre teve superfície de solo descoberto $(\mathrm{P}<0,05)$ (Tabela 4). No período de avaliação, compreendendo o ano seguinte à queima, a área queimada apresentava $12 \%$ de superfície descoberta na primavera, que se reduziu a 8,4 e $3 \%$, respectivamente, no verão, outono e inverno. O aumento na cobertura do solo desta área, no decorrer do ano, foi devido ao aparecimento de espécies de

Tabela 4 - Cobertura do solo e umidade volumétrica do solo em pastagem natural sob distintos manejos.

\begin{tabular}{lcc}
\hline \multirow{2}{*}{ Tratamentos } & Cobertura do solo & Umidade volumétrica \\
\cline { 2 - 3 } & $\%$ & $\mathrm{~g} \mathrm{~kg}^{-1}$ \\
\hline Sem queima e sem roçada & $100 \mathrm{a}$ & $277,1 \mathrm{a}$ \\
Sem queima e roçado & $100 \mathrm{a}$ & $257,9 \mathrm{~b}$ \\
Melhorado há 24 anos & $100 \mathrm{a}$ & $261,3 \mathrm{~b}$ \\
Melhorado há 7 anos & $100 \mathrm{a}$ & $262,4 \mathrm{~b}$ \\
Queima há mais de 100 anos & $93 \mathrm{~b}$ & $225,8 \mathrm{c}$ \\
\hline
\end{tabular}

Médias seguidas por letras distintas na mesma coluna diferem entre si pelo teste de Waller-Duncan a um nível de $5 \%$ de probabilidade. 
primeira sucessão, e no outono e inverno, sobretudo, à maior quantidade de material morto depositado na superfície da pastagem. Com a incidência de uma nova queima no final do inverno (término deste trabalho) houve regressão da cobertura para valores muito baixos, em função da pequena frequiência de espécies prostradas e do desaparecimento generalizado do mantilho da superfície do solo. Portanto, não chega a ocorrer cobertura completa do solo entre uma queima e outra (a cada dois anos), resultando que uma superfície considerável de solo permanece descoberto e à deriva de ventos, sol, chuva e pisoteio dos animais.

A umidade volumétrica média, na profundidade de 0 a $15 \mathrm{~cm}$, apontou para uma maior capacidade de retenção de água nas áreas sem queima, reflexo da maior cobertura do solo e da presença de restos vegetais mortos na superfície do solo (Tabela 4). Dentre os tratamentos sem queima, a umidade foi maior no SQSR, ao qual se seguiram o CNM 7 e 24 anos, o roçado e o queimado $(\mathrm{P}<0,05)$. A disponibilidade de água às plantas é um dos fatores mais importantes para o crescimento, e poderia ter sido fundamental na definição do potencial de produção de forragem dos tratamentos.

\section{CONCLUSÕES}

A queima freqüente e contínua das pastagens naturais deve ser evitada, pois promove a redução nos teores de magnésio, aumenta a acidez potencial e reduz a cobertura e umidade nas camadas superficiais do solo em relação às práticas de manejo sem queima.

O melhoramento da pastagem natural via correção e adubação do solo aumenta a fertilidade do solo.

Práticas de manejo sem queima são mais conservacionistas em termos de manutenção dos níveis de fertilidade do solo.

\section{REFERÊNCIAS BIBLIOGRÁFICAS}

COUTINHO, L.M. O uso do fogo em pastagens naturais brasileiras. In: PUIGNAU, J.P. Utilizacion y manejo de pastizales. Montivideo, Uruguay : IICA-PROCISUR (Instituto Interamericano de Cooperacion para la Agricultura), 1994. 266p. p.159-168. (DIALOGO XL).

EMBRAPA. Centro Nacional de Pesquisa de Solos. Sistema brasileiro de classificação de solos. Brasília : EMBRAPA, 1999. 412p.

ERNANI, P.R. Nutrição e produtividade de espécies vegetais em sistemas de plantio direto e convencional. In: REUNIÃO TÉCNICA CATARINENSE DE MILHO E FEIJÃO, 2, 1999 Lages. Anais... Lages : UDESC/Epagri, 1999. p.19-30.
FELLER, C., BEARE, M.H. Physical control of soil organic matter dynamics in the tropics. Geoderma, Amsterdam, v.79, p.69-116, 1997.

FERNANDES, E.C.M., MOTAVALLI, P.P., CASTILLA, C. $\boldsymbol{e}$ al. Management control of soil organic matter dynamics in tropical land-use systems. Geoderma, Amsterdam, v.79, p.49-67, 1997.

GASSEN, D.N., KOCHHANN, R.A. Benefícios de insetos de solo sob plantio direto In: NUERNBERG, N.J. (Ed.) CONCEITOS E FUNDAMENTOS DO SISTEMA PLANTIO DIRETO, 1998, Lages. Anais... Lages : SBCS/NRS, 1998. p.151-160.

GIOVANNINI, G., LUCCHESI, S. Modifications induced in soil physico-chemical parameters by experimental fires at different intensities. Soil Science, Ottawa, v.162, n.7, p.479-486, 1997.

GIOVANNINI, G., LUCCHESI, S., GIACHETTI, M. The natural evolution of a burned soil: a three-year investigation. Soil Science, Ottawa, v.143, n.3, p.220-226, 1987.

GIRARDI-DEIRO, A.M., MOTA, A.F., GONÇALVES, J.O.N. Efeito do corte de plantas lenhosas sobre o estrato herbáceo da vegetação da Serra do Sudeste, RS, Brasil. Pesquisa Agropecuária Brasileira, Brasília, v.29, n.12, p.1823-1832, 1994.

HESTER, J W, THUROW, T.L, TAYLOR JR, C.A Hydrologic characteristics of vegetation types as affected by prescrib burning. Journal Range Management, Denver, v.50, n2, p. 199-204, 1997.

MACEDO, M.C.M. A utilização do fogo e as propriedades físicas e químicas do solo. In: SIMPÓSIO SOBRE MANEJO DE PASTAGENS, 12, 1995, Piracicaba. Anais... Piracicaba: FEALQ, 1995. p.315-345.

RAISON, R.J. Modification of the soil environment by vegetation fires, with particular reference to nitrogen transformations: a review. Plant and Soil, The Hague, v.51, p.73-108, 1979 .

SALET, R.L., ANGHINONI, I., FORNARI, T.G., et $\boldsymbol{a l}$. O alumínio é menos tóxico no sistema plantio direto. In: REUNIÃO SUL-BRASILEIRA DE CIENCIA DO SOLO. Manejo de solo em sistemas conservacionistas, 1, 1996 , Lages. Anais.... Lages : SBCS, 1996. p. 72-75.

SCHACHT, W. H., STUBBENDIECK, J., BRAGG, T.B, et al. Soil quality response of reestablished grasslands to mowing and burning. Journal Range Management, Denver, v.49, n.5, p.458-463, 1996 .

SEASTEDT, T.R., COXWELL, C.C., OJIMA, D.S. $\boldsymbol{e} \boldsymbol{t}$ al . Controls of plant and soil carbon in a semihumid temperate grassland. Ecological Applications, v.4, p.344-353, 1994

STECKLING, C., ERNANI, P.R. Rendimento de massa seca de milho em função do método de aplicação de fontes de fósforo e do $\mathrm{pH}$ do solo. In: REUNIÃO SUL-BRASILEIRA DE CIÊNCIA DO SOLO. Manejo sustentável do solo, 2, 1998, Santa Maria. Anais... Santa Maria : SBCS, 1998. p.161-162.

TEDESCO, M.J., GIANELlO, C., BISSANI, C.A., et al. Análise de solo, plantas e outros materiais. 2.ed. Porto Alegre : Faculdade de Agronomia da UFRGS, 1995. 174p. (Boletim Técnico de Solos, 5).

TRACY, B.F., FRANK, D.A. Herbivore influence on soil microbial biomass and nitrogen mineralization in a northern grassland ecosystem: Yellowstone National Park. Oecologia, Berlin, v.114, p.556-562, 1998. 